\title{
Does fiscal responsibility matter? Evidence from public and private forecasters in Italy ${ }^{1}$
}

\author{
Laura Carabotta ${ }^{2}$, Ministry of Economy and Finance, Government of Italy \\ Elisenda Paluzie, Department of Economics and BEAT-CAEPS (Barcelona \\ Economic Analysis Team), Universitat de Barcelona \\ Raul Ramos, AQR-IREA, Universitat de Barcelona.
}

Abstract: Fiscal forecasts are nowadays a centerpiece of macroeconomic policy decisions, particularly in highly indebted European Union countries such as Italy. The Stability and Convergence Programs and the new Fiscal Compact seem to have improved fiscal responsibility, but have they facilitated a better accuracy of fiscal forecasters? We have compiled a new data set on fiscal forecast data for Italy covering the last two decades 1992-2014 and we have checked whether the improvement in fiscal responsibility has reduced forecasts errors. Neither the improvement in fiscal responsibility neither the political reforms reduced the optimistic bias of fiscal projections of public and private forecasters.

Keywords: fiscal forecasting, fiscal responsibility, forecast accuracy, public and private forecasters, Evaluating forecasts, Government forecasting.

\footnotetext{
1 This paper was presented in seminars at the AQR Group of the Universitat de Barcelona, at CER Centro Europa di Ricerche - in Rome, (Italy), and at the Ministry of Economics and Finance of Italy Treasury's Department. It was also presented at the $\mathrm{PhD}$ day at the Universitat de Barcelona, at the 14th IWH-CIREQ Macroeconometric Workshop in Halle (Germany) in December 2013, at Xrepp PhD day at the Universitat de Barcelona in March 2014 and in the Workshop of Time Series Econometrics in Zaragoza (Spain) in April 2014. The paper was also accepted at the Prague Macroeconomics and Finance Conference (Czech Republic), the International Conference on Applied Business and Economics (ICABE) in New York (USA), the International Academic Conference in Istanbul, (Turkey), the XVII Encuentro de Economía Aplicada in Gran Canaria (Spain) and Time Series-ITISE 2014 University of Granada (Spain). We gratefully acknowledge comments from participants in all these seminars and conferences, as well as the comments of referees and IJF's editors that helped us to improve the paper. Financial support from the Catalan government (2014 SGR1257 and 2014 SGR1362) and from the Spanish Ministry of Economics and Competitiveness (ECO2016-78991-R AIE/FEDER, UE and ECO2016-75805-R, AIE/FEDER, UE) is gratefully acknowledged.

${ }^{2}$ Corresponding author: Laura Carabotta, laura.carabotta@mef.gov.it. The information and views set out in this publication are those of the author and do not reflect necessarily the official opinion of the Ministry of Economy and Finance of Italy.
} 


\section{Introduction}

Since the signature in 2012 of the Treaty on Stability, Coordination and Governance (TSCG) aimed at strengthening fiscal discipline and introducing stricter surveillance within the euro area, forecasts of the fiscal budget for European countries are used during the European semester as the basis for fiscal planning. For this reason, it is crucial to understand the different sources of fiscal forecasts errors and try to improve forecast accuracy in order to achieve a better planning. Moreover, as too optimistic forecasts make more difficult to fulfil the budget deficit objectives, improving forecast accuracy is a key policy issue in highly indebted countries like those of the South of Europe.

Econometric studies have recently analysed the determinants of fiscal forecasts errors. The main determinants analysed by the literature are fiscal rules and fiscal responsibility; political and economic variables; and the nature of the forecaster.

Fiscal rules are constraints on fiscal policy through numerical limits on budgetary aggregates aimed at containing pressures to overspend and ensure fiscal responsibility and debt sustainability. The Stability and Growth Pact (SGP) established in 1997 in the European Union was centered in these type of numerical fiscal rules. However, fiscal responsibility is a broader set of measures that have the objective of achieving fiscal sustainability over the long run. They include, among others, the setting of independent fiscal institutions-as the Fiscal Council-, transparency standards, and surveillance and enforcement mechanisms.

An improvement in fiscal responsibility may affect the performance of the forecast errors through different mechanisms. Frankel (2011) and Frankel and Schreger $(2013,2016)$ have found evidence that numerical fiscal rules such as those included in the Stability and Growth Pact tend to increase the biasedness of the official forecasts of growth and budget deficits as they incentive government's tendency to satisfy fiscal targets by wishful thinking. On the contrary, other type of rules at the national level, such as the creation of an independent fiscal institution that provides independent forecasts may reduce the bias in forecasts.

Political variables influence the fiscal errors in several ways: the effect on fiscal performance of the electoral cycle when it is considered jointly with the output gap is significant during upturns (Merola and Pérez, 2013). Various authors conclude that deviations from the budget balance forecasts are partially explained by electoral cycles (Bruch and Stephan, 2006; Giuliadori and Beetsma, 2008; von Hagen, 2010) but also by the degree of fragmentation and other political variables (Pina and Venes, 2011; Frankel and Schreger, 2013). 
The economic cycle also influences forecasts in a direct and indirect way. In periods close to turning points, it is more difficult to obtain good fiscal forecasts due to the uncertain response of automatic stabilisers, but also due to the lower precision of GDP forecasts. In particular, if GDP forecasts tend to be optimist (or pessimist), fiscal forecasts, particularly revenues, will also move in the same direction (Buettner and Kauder, 2015). The literature has concluded that higher GDP forecasts errors imply higher fiscal forecasts error (Merola and Pérez, 2013). Other researchers note that when growth is not rich, the government tends to provide output growth forecasts more rosy than realistic and this is because there is an attempt to push up the budget balance forecasts (Bruch and Stephan, 2006; Pina and Venes, 2011; Beetsma et al., 2013).

The nature of the forecaster might also influence the quality and the accuracy of the forecasts errors. ${ }^{3}$ In particular, there is a vast literature about the importance of private agencies in providing fiscal forecasts. Many studies demonstrate that independent budget forecasting could contrast the overly optimistic forecasts provided by the national and international agencies (Jonung and Larch, 2006; Debrun et. al., 2009 and Merola and Pérez, 2013, among others). The main result is that official forecasts are usually more over-optimistic than private forecasts (Abreu, 2011; Frankel and Schreger, 2016). Jalles et al (2015) also provide evidence of the quality of private sector forecasts of the budget balance considering a sample of 29 advanced and emerging countries between 1993 and 2009. They conclude that adding private sector forecasts in the policy process could be useful given their lower 'optimism bias' compared to government forecasts, but they also show that private sector forecasts also have several limitations and could be improved.

Our contribution on the literature follow all these lines. In particular, we investigate if fiscal forecasts errors are rational and accurate for public (national and international) and private forecasters and if after the introduction of the SGPs and the new fiscal compact in Italy, fiscal responsibility pushed the different agencies to modify their fiscal forecasts. With this aim, a new data set on fiscal forecasts for Italy has been compiled and standard forecasting competition methods are applied.

The Italian case is particularly relevant because of its increasingly high debt levels. Italian debt has been over $100 \%$ of GDP for most of the past two decades. During the years 1994-1996, the debt went over 106\% of GDP, then decreased from 1998-

\footnotetext{
3 In addition, a recent strand of the literature on fiscal forecasting shows that the quality of forecasts is crucially affected by the information set used. In particular, it has been proven that the use by analysts of quarterly and monthly fiscal data, together with higher frequency macroeconomic indicators, include significant information when predicting annual budgetary outcomes. It has been shown that the use of this information helps improving fiscal forecasts by international organizations, that in the European case play a key role in monitoring compliance with fiscal rules. Along these lines see Ghysels and Ozkan (2015), Pedregal and Pérez (2010) and Pérez (2007).
} 
2000 and then increased again in 2008 to $127 \%$ of GDP against the EU average of $68 \%$. In 2015 it is projected to peak at $132.7 \%$ and to gradually decline to $123.8 \%$ in $2019^{4}$. Although the public deficit had been reduced to $2.6 \%$ of GDP in 2015, the driver of the increase in public debt is the large gap between high implicit rates paid on debt $(4.2 \%$ on average) and nearly zero average annual nominal GDP grow ($1.3 \%$ real GDP growth and $+1.4 \%$ deflator), i.e. the snow-ball effect. ${ }^{5}$

Italy experienced a double-dip Great Recession which was a result of the sovereigndebt crisis of the mid-2011, when Italy's economy was severely hit by increased risk aversion in financial markets. In fact, at the onset of the 2008 crisis, Italy's public finances were in relatively good shape. ${ }^{6}$ However, the government had little room to implement countercyclical policies because of the high levels of public debt. Moreover, not only GDP fell more in Italy than in most other European countries but its recovery was much lighter. Until 2011, the reaction of Italian governments consisted only on light Budget Laws mostly aimed at maintaining the stabilization of public finances and reducing the contagion effect of the financial crisis. The 2008 "anticrisis decrees" increased tax audits and VAT on televisions services and introduced a tax amnesty aimed at the return of capital stocks from abroad. It was only in 2011 that serious fiscal consolidation started, and these measures were reinforced and expanded by the technocratic government of Mario Monti that was appointed in late 2011. Most of the policy changes involved tax increases (reintroduction of real estate taxation on the main residence, increase in the VAT standard rate from $20 \%$ to $22 \%$ ) and budget cuts (cuts in social benefits and public sector pay, reform of the pension system). These measures amounted to $3.1 \%$ of GDP in 2012 and to 4.7\% in 2013. (See Figari and Fiorio, 2015, for an in-depth analysis of fiscal consolidation policies in Italy).

In the institutional side, the 2012 constitutional reform amended articles 81, 97, 117, 119 of the Constitution, inserting the principle of the "balanced budget". The reform established also that the harmonisation of public accounts would be an exclusive competence of the State, while before it was shared between the State and the Regions. The new Constitutional Law left for a reinforced law the establishment of the maximum deviation from the parameter of equilibrium in the budgets. This reinforced law, passed in December 2012, set up a fiscal independent authority linked to the Parliament, the Parliamentary Budget Office (PBO), which is similar to the fiscal councils already adopted elsewhere in Europe. This fiscal authority analyses and verifies the performance on the public finances and produces

\footnotetext{
${ }^{4}$ European Commission, Council recommendation on the 2016 national reform programme of Italy, Brussels, 18-5-2016.

${ }^{5}$ European Commission, Country Report Italy 2016.

${ }^{6}$ In 2007 public deficit was 1.3\% of GDP after three years above the 3\% threshold imposed by the Stability and Growth Pact and the EC recommended that Italy be removed from the Excessive Deficit Procedure started in 2005.
} 
independent forecasts. However, as the new Constitutional Law stated that the new constitutional rules shall apply as of the fiscal year starting in 2014, the PBO only became operational in 2014, very late as compared with the majority of European countries. The result of these reforms is that the improvement in fiscal responsibility has been more marked than in other European Union countries with similar conditions at the beginning of the nineties of the last century.

Figure 1 shows the average value of the European Commission's Standardised fiscal rules index for Greece, Portugal, Ireland and Italy for two different subperiods: 1994-2000 and 2001-2014. The European Commission has compiled a dataset on domestic fiscal rules in force since 1990 across EU countries. The dataset covers all types of numerical fiscal rules (budget balance, debt, expenditure, and revenue rules) at all levels of government (central, regional, and local, general government, and social security). The fiscal rule index combines information on the strength of the different fiscal rules (the statutory base of the rule, the room for revising objectives, the mechanisms of monitoring compliance and enforcement of the rule, the existence of pre-defined enforcement mechanisms, and media visibility of the rule) and its coverage. The minimum value of the standardised index is -1 (indicating that there is no rule or that they are ineffective) while the maximum value between 1990 and 2014 is 3.5 .

From figure 1, we can see that Italy and Portugal have moved from a low level of fiscal responsibility (close to -1 between 1994 and 2000) to a medium level with values close to zero during 2001-2014 (in the case of Italy, positive but in the case of Portugal just below zero), while Greece and Ireland have not performed so well during the second subperiod.

In the political side, the Italian parliamentary system was particularly fractionalized for most of the post-war decades. ${ }^{7}$ However, the introduction of new rules to increase the number of seats of the majority reduced this fractionalization in the last decade of our sample. In 2005, the majority bonus system (a jackpot system offering a fixed number of total seats to the winning party or alliance regardless of their relative votes) was introduced at the national level. In 2013, after a ruling from the Constitutional Court stating that unlimited bonuses were unconstitutional, the system was modified, with the establishment of a $40 \%$ minimum threshold for the assignment of the bonus, with a runoff ballot between the two most voted parties if the threshold was not reached.

\footnotetext{
${ }^{7}$ A high number of democratic checks were introduced in order to prevent the rise of a autocratic leader like Benito Mussolini.
} 
Figure 1. European Commission's Standardised fiscal rules index

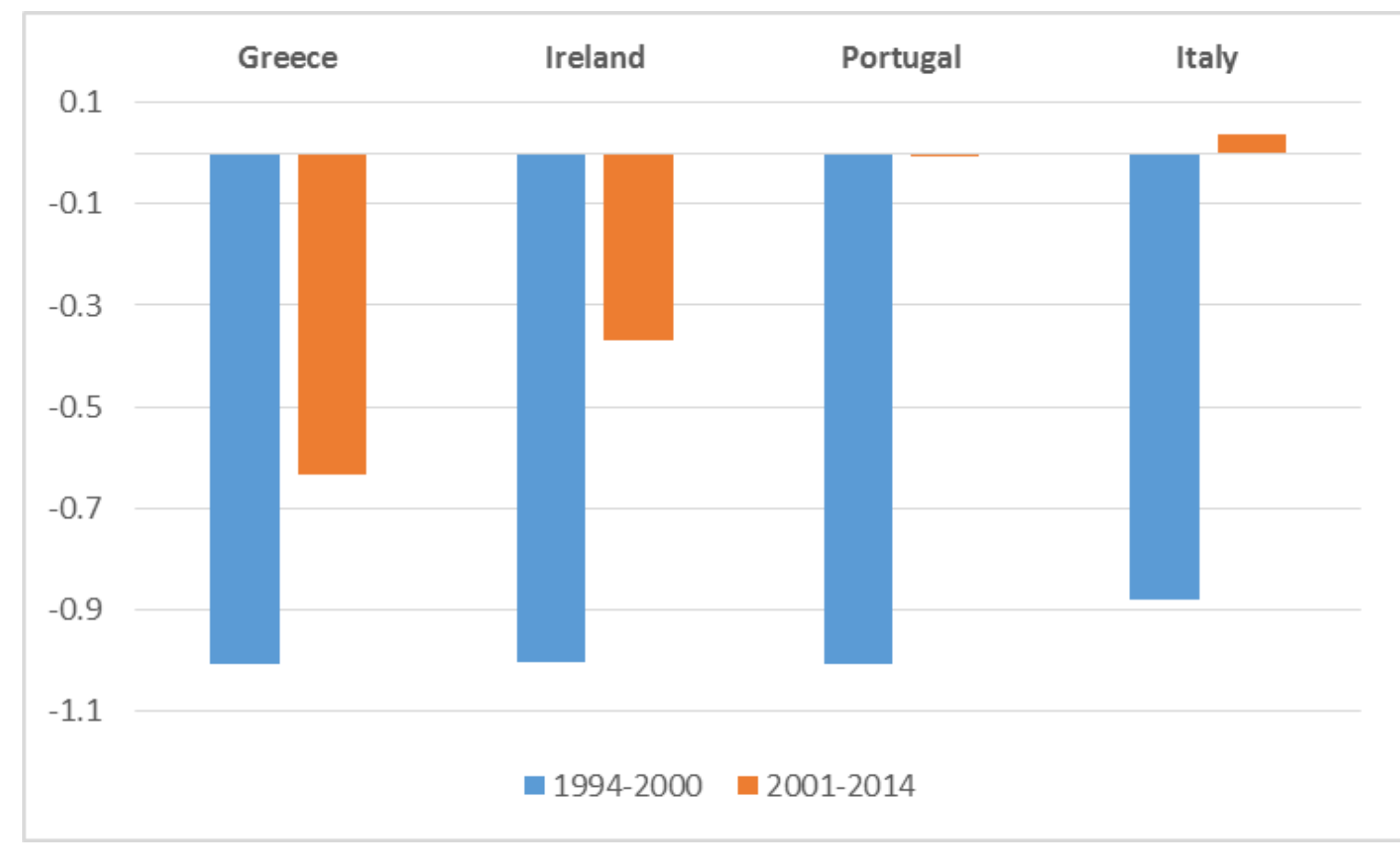

Own elaboration from the EC Fiscal Rules Database available at http://ec.europa.eu/economy finance/db indicators/fiscal governance/fiscal rule s/index en.htm

Given this context, the main objective of the paper will be to analyse whether the improvement in fiscal responsibility has reduced forecasts errors both for public and private forecasters; and whether institutional and political factors have influenced the accuracy of fiscal forecasts in Italy, during the period 1994-2014.

The rest of the paper is organised as follows. Section 2 provides information on the databases used for the study, the variables considered and their different availability. In Section 3 we describe the methodology used in our analysis while Section 4 presents the obtained results. Last, Section 5 summarises the main conclusions of the paper. 


\section{Data}

Budget forecasting may look like the exclusive task of Ministries and international institutions. Yet many other expert forecasters, like commercial or investment banks, industry, semi-governmental agencies, and university departments have produced budget forecasts too. In recent years, some datasets have become available that include deficit forecasts from a larger set of expert forecasters over a continuous period of time. One of those datasets comes from Consensus Economics Forecasts (CEF). This company conducts a survey in several OECD countries among professional economists working for commercial or investment banks, industry, government based agencies, and university departments. Most of the surveyed experts are at domestic institutions that provide forecasts for a single country only; a few work for international financial institutions or research institutes that provide forecasts for several countries simultaneously.

The CEF survey has gradually expanded its scope and coverage, and provides us with a large panel of private forecasters. The monthly survey on Italy covers 42 forecasters from 1992 to 2015. However, despite the gradual expansion of the dataset, fiscal forecasts have not always received the same attention by forecasters over time. Some forecasters stopped producing projections for the budget balance, while others that were initially included left the sample owing to closure, mergers, or other reasons. Moreover, new forecasters joined the CEF survey only at a later stage.

The survey makes enquiries of respondents the first week of each month about current and year ahead forecasts for a number of macroeconomic variables. Forecasts of longer horizons are not included, but may not be interesting as the literature shows that budget forecasts are surrounded by substantial uncertainty and large biases (Favero and Marcellino, 2005). The Consensus forecasts are published early in the second week of the same month.

The sample used in our analysis is, therefore, a subset of the entire group of expert forecasters included in the CEF survey. In particular, we only consider those forecasters providing regular forecasts of public deficit forecasts for the current year $\left(d_{f, t}\right)$ and the year ahead $\left(d_{f, t+1}\right)$ from 1994 to 2014 . This reduces the panel to a selection of three private forecasters among Italian banks and research institutes ${ }^{8}$

8 The private forecasters include Banca Commerciale, Banca di Roma, Banca IMI, Banca Intesa, Banca Nazionale del Lavoro, Bank of America, Caboto, Capitalia, Cariplo Spa, Centro Europa Ricerche, Chase Manhattan - Milan, Citigroup, Cofiri SIM, Confindustria, Credito Italiano, Deutsche Bank, Euromobiliare, ENI, Econ Intelligence Unit, Fiat SpA, Goldman Sachs, FAZ Institut, ING Financial Markets, HSBC, IHS Global Insight, IRS, ISAE, Intesa Sanpaolo, ISCO, 
(Confindustria, ENI and Prometeia) and three international agencies: the Organisation for Economic Co-operation and Development (OECD), the European Union (EU), and the International Monetary Fund (IMF). We also analyse the data provided by the Ministry of Economy and Finance (MEF). The international institutions do not produce forecasts on a monthly basis. Instead, generally speaking, they produce their projections twice a year (in Spring and Autumn), at different moments. The OECD publishes its forecasts in June and December in the Economic Outlook; the IMF forecasts are published in the World Economic Outlook; and forecasts by the EC are released in May and October. The publication of forecasts by the Italian Ministry of Economy and Finance is part of the "Economic and Financial Planning Document (DPEF)" from 1992 to 2010, and the "Economic and Financial document (DEF) and the Update of the Economic and Financial document" from 2011 to 2014 that are used by the Italian Government when submitting the budget to Parliament. These forecasts are produced in June, July, and October. Taking this into account, we have considered two samples: one sample containing only forecasts vintages produced during the second semester of the year and another one containing forecasts produced both in the first and second semester of the year. In case more than one forecast is available for a particular forecaster during each semester of the year, we have calculated the simple average, although in most cases, only a single forecast was available or forecasts did not vary substantially or even at all.

In some cases, the forecasts required some transformation before they could be used in the empirical analysis. CEF asks respondents for a forecast of the overall balance in nominal terms. ${ }^{9}$ In order to transform this forecast into one of the budget balance as a ratio to GDP, we divide the forecast of the nominal balance (surplus) for year $t+1$ in a certain month $m$ by the GDP forecast for the same year. As the CEF only provides forecasts of GDP growth rates, we compute the year ahead nominal GDP forecast by applying the CEF growth rate to the latest available estimate for the same year GDP.

Last, it is important to mention that although we are covering a 21 year-period, there are some missings in forecasts by private institutions. For this reason, we will consider, first, a balanced panel for forecasts produced during the second semester covering 17 periods: 1994-2000, 2003-2008, 2010-2011 and 2013-2014; and an unbalanced panel covering 21 years (from 1994 to 2014). As a result, the first data set has 119 observations (17 forecasts by 7 forecasters) for the current year deficit and another 119 for the deficit one-year-ahead. This period covers seven years of low fiscal responsibility (1994-2000) and ten years of medium fiscal responsibility

Istituto Bancario Italiano, JP Morgan, Prometeia, Morgan Stanley, RASFIN, Salomon SB Citibank, Studi Finanziari, Schroder SSB Citibank, UBS, UniCredit, UniCredit Banca Mobiliare.

${ }^{9}$ For Italy, specialists forecast the general budget balance for the calendar (end of the) year. 
(2003-2008, 2010-2011 and 2013-2014). It also covers different subperiods in terms of good and bad macroeconomic performance. In particular, the following 12 years are classified as good times (1994, 1995, 1997-2000, 2004-2007 and 2010) with GDP growth clearly above $1.0 \%$ and the other 5 are classified as bad times (1996, 2003, 2008, 2011 and 2013). The whole sample with forecasts produced during the second semester has 142 observations (instead of $147=21$ year per 7 forecasters). The whole dataset including forecasts produced from the first semester of 1994 to the second semester of 2014 by the 7 forecasters has 259 observations.

The series representing actual data and forecasts of the deficit to GDP ratio for this period is the registered deficit to GDP ratio $\left(d_{t}\right)$ from the OECD's database (OECD iLibrary- Economics: Key tables from OECD). We have collected data for the first estimates of the series, although robustness checks using final data show similar results to the ones presented here and are available from the authors on request.

The econometric analysis of the determinants of forecast errors have also required the use of additional information. In particular, we have collected data from the OECD's database about the output gap and the level of debt as a percentage of GDP covering the period of interest. We have also controlled for different political variables: we have built a dummy taking value 1 for those years with elections and we have also considered a variable capturing fractionalization in the political system from the Database of Political Institutions of the World Bank for the period 19942012 (Beck et al, 2001). In particular, the considered variable is the "Margin of Majority" that reflects the fraction of seats held by the government. It is calculated by dividing the number of government seats by total (government plus opposition plus non-aligned) seats.

More details on the data sources used in this study are provided in Appendix 1.

\section{Methodology}

\subsection{Assessing forecast errors}

In this section we describe the techniques used to assess forecast accuracy. Forecast error is defined as the difference between the actual deficit $d_{t}$ at time $\mathrm{t}$ (and $d_{t+1}$ the actual deficit at time $\mathrm{t}+1$ ) and the forecasted value $d_{f, t}$ at time $\mathrm{t}$ (and $d_{f, t+1}$ at time $\mathrm{t}+1$, respectively):

$$
\begin{gathered}
e_{f, t}=d_{t}-d_{f, t} \\
e_{f, t+1}=d_{t+1}-d_{f, t+1}
\end{gathered}
$$


We compute different accuracy statistics based on both forecast errors:

a) ME mean error

Following Keereman (1999), the mean error is equal to the mean forecast minus the realized average.

$$
\mathrm{ME}=\frac{1}{\mathrm{n}} \sum_{\mathrm{t}=1}^{\mathrm{n}} \mathrm{e}_{\mathrm{t}}
$$

The drawback of this measure is that positive and negative errors can offset each other and thus reduce the size of the error. The mean squared error takes this into account.

\section{b) MAE Mean absolute error}

The mean absolute error measures the size of the difference between the values in the projections and the values associated with the actual outcome. Since the absolute value is used, this prevents deviations with opposite signs from cancelling each other out.

$$
\mathrm{MAE}=1 / \mathrm{n} \sum_{\mathrm{t}=1}^{\mathrm{n}}\left|\mathrm{e}_{\mathrm{t}}\right|
$$

\section{c) RMSE Root of the mean squared error}

While with the mean error positive and negative deviations of the projection from the actual data can cancel out, this is not the case with the MSE. A MSE of zero means that there is perfect accuracy. Large errors are usually considered more harmful than small differences between forecasts and real data. To penalize large mistakes, a root mean squared error (RMSE) can be used. The RMSE is frequently used as a measure of the difference between the predicted values and the values that are actually observed. These individual differences are also called residuals and the RMSE serves to aggregate them into a single measure of predictive power. A large RMSE indicates a lower level of accuracy.

$$
\mathrm{RMSE}=\sqrt{\frac{1}{\mathrm{n}} \sum_{\mathrm{t}=1}^{\mathrm{n}} e_{t}^{2}}
$$




\section{d) Diebold-Mariano Test:}

We also apply the Diebold and Mariano (1995) test of predictive accuracy and compare forecasts by each institution with a benchmark international public forecaster (OECD). The DM test supposes that a forecaster has an identical loss function $g(A, B)$ so that two different forecasts, $A$ and $B$, lead to similar losses due to errors. Let $g\left(e_{A, t}\right)$ and $g\left(e_{B, t}\right) g\left(e_{B, t}\right)$ denote the loss from a forecast error evolving from a prediction model $\mathrm{A}$ and $\mathrm{B}$, with $\hat{\sigma}$ denoting a consistent estimate of the standard deviation of the difference of losses. The null hypothesis is that $g\left(e_{A, t+h}\right)=g\left(e_{B, t+h}\right) g\left(e_{A, t+h}\right)=g\left(e_{B, t+h}\right)$, and DM is simply distributed as $N(0,1)$ under this null (Diebold and Mariano, 1995).

$$
\mathrm{DM}=\frac{\frac{1}{\mathrm{~T}} \sum_{1}^{\mathrm{t}}\left\{\mathrm{g}\left(\mathrm{e}_{\mathrm{A}, \mathrm{t}+\mathrm{h}}\right)-\mathrm{g}\left(\mathrm{e}_{\mathrm{B}, \mathrm{t}+\mathrm{h}}\right)\right\}}{\hat{\sigma}_{\llbracket \mathrm{g}\left(\mathrm{e} \rrbracket_{\mathrm{A}, \mathrm{t}+\mathrm{h}}\right)-\left[\mathrm{g}\left(\mathrm{e} \rrbracket_{\mathrm{B}, \mathrm{t}+\mathrm{h}}\right)\right.}}
$$

\subsection{Bias in forecasts}

A forecast is considered optimal when it meets certain properties, as discussed in Timmermann (2007). In particular, forecasts should be unbiased in the errors and have no serial correlation. In the literature, whenever these two properties are present, a forecast is called weakly efficient. In this section we consider all forecasts for variables $d_{f, t}$ and $d_{f, t+1}$ provided by each agency and for the selected months.

To achieve this, following the works of Artis and Marcellino $(1998,2001)$ and Keerman (1999), we compute a model where we formally analyze the unbiasedness and serial correlation of the forecasts by the following equations:

$$
\begin{gathered}
\mathrm{d}_{\mathrm{t}}=\alpha_{0}+\alpha_{1} \mathrm{~d}_{\mathrm{f}, \mathrm{t}}+\mu \\
\mathrm{d}_{\mathrm{t}+1}=\alpha_{0}+\alpha_{1} \mathrm{~d}_{\mathrm{f}, \mathrm{t}+1}+\mu
\end{gathered}
$$

We test unbiasedness with a Wald test and check if the coefficient parameters comply with the following null hypotheses:

$$
\alpha_{0}=0 \text { and } \alpha_{1}=1
$$

The term $\mu$ is an error term that under the null hypothesis of unbiasedness coincides with the forecast error (Clements and Hendry, 1997). 
Holden and Peel (1990) also showed that this condition is sufficient but not necessary for unbiasedness and suggested that the condition $\beta_{0}=0$ should be included in the regression:

$$
\begin{gathered}
\mathrm{e}_{\mathrm{f}, \mathrm{t}}=\beta_{0}+v_{\mathrm{t}} \\
\mathrm{e}_{\mathrm{f}, \mathrm{t}+1}=\beta_{0}+v_{\mathrm{t}+1}
\end{gathered}
$$

where $e_{f, t}$ and $e_{f, t+1}$ are the error terms and $v_{t}$ and $v_{t+1}$ are the demeaned forecast errors. Weak efficiency further requires that the forecast errors be uncorrelated across time (Clements and Hendry, 1997).

\subsection{Econometric determinants of forecast errors}

The panel data models that we use in order to identify the determinants of forecasts errors and to check whether the improvement in fiscal responsibility has had differential effects between public and private forecasters are the following ones:

$$
\begin{gathered}
\mathrm{e}_{\mathrm{f}, \mathrm{i}, \mathrm{t}}=\delta_{1} \mathrm{e}_{\mathrm{y}, \mathrm{i}, \mathrm{t}}+\delta_{2} \operatorname{ogap}_{t-1}+\delta_{3} \text { debt }_{t-1}+\delta_{4} \text { fiscalresp }_{t}+\delta_{5} \operatorname{good}_{t}+\delta_{j} X_{t}+\theta_{\mathrm{i}}+\nu_{\mathrm{i}, \mathrm{t}} \\
\mathrm{e}_{\mathrm{f}, \mathrm{i}, \mathrm{t}+1}=\delta_{0}+\delta_{1} \mathrm{e}_{\mathrm{y}, \mathrm{i}, \mathrm{t}+1}+\delta_{2} \operatorname{ogap}_{t}+\delta_{3} \text { debt }_{t}+\delta_{4} \text { fiscalresp }_{t}+\delta_{5} \operatorname{good}_{t}+\delta_{j} X_{t}+\theta_{\mathrm{i}}+\nu_{\mathrm{i}, \mathrm{t}+1}
\end{gathered}
$$

where $e_{f, i, t}$ refers to errors in forecasting fiscal public balance for the current year by forecaster $i$ and is defined as in equation (1) while $e_{\mathrm{f}, \mathrm{i}, \mathrm{t}+1}$ refers to errors for one year ahead forecasts by the same forecasters as defined in equation (2). The terms $e_{y, i, t}$ and $e_{y, i, t+1}$ denote errors in forecasting GDP for the current year and one-year-ahead by forecaster $i$, respectively. The term ogap denotes output gap while debt refers to the level of debt as a percentage of GDP. Both variables are invariant in respect to the different forecasters. Fiscalresp is a dummy variable that takes value one when the level of fiscal responsibility is medium according to the standardised fiscal rule index by the European Commission and 0 when the level is low. As previously explained, for the case of Italy, this corresponds exactly to the period 2001-2014 when a medium level of fiscal responsibility was adopted and to 1994-2000 when the level was low. The variable good is a dummy variable taking value one with GDP growth above $1.0 \%$ and 0 otherwise. Equations (12) and (13) are enlarged with some additional variables $\left(X_{t}\right)$ related to political variables that could influence forecast accuracy. In particular, we have included a dummy for elections year that takes value 1 every time year $t$ is an election year and 0 otherwise, and the variable "Margin of majority" that has been described in Section 2. All the models also include forecasters fixed-effects $\left(\theta_{i}\right)$, in order to capture time-invariant characteristics of different forecasters. The analysis of potential differences in the impact of improving fiscal responsibility on forecasting accuracy depending on the nature of the forecaster will be carried out by estimating equations (12) and (13) by different 
subsets of forecasters. As in Merola and Pérez (2013), all models are estimated using Instrumental Variables with lagged GDP forecast errors and time dummies as excluded instruments.

\section{Results}

Table 1 shows the comparison of the MA, MAE, and RMSE for the pool of forecasters distinguishing between public and private agencies, but also for individual forecasters for current year and year ahead forecasts ${ }^{10}$.

The obtained results are consistent with previous studies. We find higher RMSE for one year ahead forecasts than for the current year ones (Keereman, 1999, Artis and Marcellino 1998, 2001). Positive value for forecasts errors are usually associated in the literature to "pessimism" about the evolution of the budget balance while negative values for the error denote 'optimistic' perspectives. When analysing the common period, the mean error for the pool of forecasters for the current year deficit is -0.231 , while for the one year ahead is -0.049 . While for the current year deficit all the forecasters show a similar pattern providing optimistic forecasts, there are differences regarding one year ahead forecasts: MEF and the EC provide pessimistic forecasts while the rest of public forecasters (IMF and OECD) and all private forecasters provide optimistic ones. Similar results are obtained when considering the unbalanced samples.

We can also see from results in Table 1 that forecasts errors are higher for private than for public forecasters for the current year deficit but that they are quite similar when looking at the one year ahead forecast errors. This result is consistent with the results obtained in the literature. Public forecasts tend to increase their optimistic bias the longer the horizon (Frankel, 2011, Frankel and Schreger, 2013, 2016) One reason might be upward bias in GDP growth forecasts as governments may use GDP forecasts in a strategic manner. Indeed, Jonung and Larg (2006) found that EU governments systematically overestimated the economic growth rate, and this tendency was especially strong in Italy and Germany.

On the contrary, in the current year, public forecasts might be more accurate than private ones because of access to private information (data on current-year budgetary execution, information on policy measures, etc.), not available to private forecasters or international agencies (Merola and Perez, 2013).

Table 3 shows the results of the Diebold-Mariano tests comparing the forecast accuracy in terms of the RMSE of every individual forecaster compared to the

\footnotetext{
${ }^{10}$ All calculations have been carried out using STATA 14.2. The results for the Diebold-Mariano test have been obtained using the routine dmariano from Christopher F. Baum.
} 
OECD. Looking at the results in the first column of table 3, we can see that the OECD has provided more accurate forecasts for the current year deficit than the MEF, the EC, ENI and Prometeia and, at usual levels of statistical significance, we cannot reject the null hypothesis that forecasts have similar levels of accuracy for the IMF and Confindustria. For the one year ahead deficit, there are no significant differences between the OECD, the EC and private forecasters although the OECD provides better forecasts than MEF and the IMF. Table 2 provides the same summary statistics as in Table 1 , but splitting the considered samples into two periods: those years associated with low levels of fiscal responsibility and those with medium levels of fiscal responsibility. No clear improvement in RMSE is observed when comparing both periods either across the pool of forecasters or when considering the different subgroups. Results in the second and third column of Table 3 do not show any significant difference regarding the relative accuracy of individual forecasters in the two subperiods when compared to the conclusions obtained when looking at the whole period.

Tables 4 and 5 show the results of the analysis of unbiasedness and efficiency of the forecasts for the current year and the one year ahead, respectively, distinguishing between public and private forecasters and between periods of low versus medium fiscal responsibility. To test for bias, we look at whether the mean forecast error is significantly different from zero. Forecasts are unbiased if we cannot reject the null hypothesis that the estimated coefficient is equal to zero. However, if the estimated coefficient is negative, forecasts are biased toward optimism. As we can see from the results in table 4, the hypothesis of unbiadnesses is rejected in all cases with negative values for the estimating intercept reinforcing the idea that forecasters are biased towards optimism. The Wald test for a null hypothesis that the intercept is equal to zero and the slope equal to one is also rejected in all cases, implying that forecasts are unefficient. As in the previous analysis, a higher fiscal responsibility has not implied any improvement in the behaviour of forecasts nor private nor public. However, there are other factors that could influence the forecast accuracy in the two subperiods and that should be controlled for in order to carry out a proper comparison. For instance, it could be the case that institutions have changed the frequency of the data used to analyse fiscal forecasts between the two periods (i.e. from annual to quarterly and next they aggregate forecasts), or perhaps they have changed the approach and instead of forecasting the government deficit directly now they forecast government revenues and expenditures separately and then calculate the deficit (or the opposite) or the model specifications could be different in the two periods. Unfortunately, the data sources used in our analysis do not provide information on the methods and techniques used by each institution to obtain fiscal forecasts. 
Table 6 and table 7 present the results of estimating by instrumental variables the models specified in equations (12) and (13) for the current year fiscal forecast errors and the one year ahead fiscal forecast errors, respectively.

As in Merola and Perez (2013), higher GDP forecast errors have a positive impact on fiscal forecasts errors in most specifications, both for the current year and the year ahead. The positive sign of the coefficient indicates that a negative GDP growth shock produces optimistic fiscal balance forecasts.

In most specifications, the lagged out gap is not statistically significant at the usual levels, but in the few models where the null hypothesis of non-significance is rejected, the sign is negative. This result is in line with Pina and Venes (2011) and Barroso and Mendoza (2015) and it indicates that, on average, forecasters do not provide optimistic forecasts when the output gap was positive in the previous year and vice versa.

Regarding the coefficients on the ratio of public debt on GDP, the sign is negative in most models (greater debt is associated with more pessimistic forecasts) and its statistical significance is clear in models for the one-year ahead deficit. This result can be explained by the adoption of fiscal consolidation programmes during the considered period. However, the coefficient associated to the dummy for higher fiscal responsibility is negative and significant in most specifications for the current year deficit with no significant differences between public and private forecasters thus contributing to optimistic fiscal forecasts. However, it is not significant for the one year ahead fiscal forecast errors.

As for the other controls, the dummy for good times is significantly different from zero and negative and thus, contribute to optimistic fiscal forecasts. This result is different from that obtained by Merola and Perez (2013) where the good times dummy was positive and significant but is in line with Frankel (2011) and Frankel and Schreger (2013) results that found that official forecast were specially subject to wishful thinking during booms.

As for the political variables included, electoral years is also negative and significant thus contributing to optimistic fiscal forecasts which is consistent with findings in the literature. Finally, when significant, the variable associated to the margin of majority has a negative effect on errors, indicating that when the fraction of seats held by the government is higher, fiscal forecasts are more optimistic. 
Table 1. Analysis of the forecast accuracy of public and private agencies

\begin{tabular}{|c|c|c|c|c|c|c|c|c|c|}
\hline \multirow[t]{2}{*}{ Deficit current year } & \multicolumn{3}{|c|}{ Autumn forecasts (common 119 obs) } & \multicolumn{3}{|c|}{ Autumn forecasts (unbalanced 142 obs) } & \multicolumn{3}{|c|}{ Spring \& Autumn (unbalanced 259 obs) } \\
\hline & ME & MAE & RMSE & ME & MAE & RMSE & ME & MAE & RMSE \\
\hline Pool & -0.231 & 0.449 & 0.567 & -0.118 & 0.470 & 0.616 & -0.110 & 0.578 & 0.724 \\
\hline Public & -0.169 & 0.431 & 0.541 & -0.054 & 0.439 & 0.581 & -0.039 & 0.528 & 0.658 \\
\hline $\mathrm{MEF}$ & -0.123 & 0.464 & 0.584 & 0.008 & 0.483 & 0.634 & 0.008 & 0.483 & 0.634 \\
\hline $\mathrm{EC}$ & -0.140 & 0.442 & 0.561 & -0.035 & 0.436 & 0.597 & 0.032 & 0.548 & 0.670 \\
\hline IMF & -0.252 & 0.424 & 0.496 & -0.116 & 0.449 & 0.548 & -0.113 & 0.571 & 0.682 \\
\hline OECD & -0.160 & 0.394 & 0.519 & -0.072 & 0.385 & 0.540 & -0.059 & 0.487 & 0.633 \\
\hline Private & -0.314 & 0.474 & 0.599 & -0.211 & 0.517 & 0.663 & -0.202 & 0.644 & 0.802 \\
\hline Confindustria & -0.242 & 0.428 & 0.541 & -0.201 & 0.432 & 0.539 & -0.211 & 0.577 & 0.709 \\
\hline ENI & -0.290 & 0.543 & 0.643 & -0.147 & 0.584 & 0.711 & -0.109 & 0.666 & 0.802 \\
\hline Prometeia & -0.408 & 0.450 & 0.609 & -0.285 & 0.525 & 0.714 & -0.291 & 0.672 & 0.868 \\
\hline \multirow[t]{2}{*}{ Deficit 1 year ahead } & \multicolumn{3}{|c|}{ Autumn forecasts (common 119 obs) } & \multicolumn{3}{|c|}{ Autumn forecasts (unbalanced 142 obs) } & \multicolumn{3}{|c|}{ Spring \& Autumn (unbalanced 259 obs) } \\
\hline & ME & MAE & RMSE & ME & MAE & RMSE & ME & MAE & RMSE \\
\hline Pool & -0.049 & 1.016 & 1.281 & 0.067 & 1.038 & 1.274 & 0.008 & 1.145 & 1.409 \\
\hline Public & 0.025 & 1.051 & 1.284 & 0.145 & 1.072 & 1.274 & 0.056 & 1.181 & 1.423 \\
\hline MEF & 0.140 & 1.126 & 1.344 & 0.282 & 1.144 & 1.335 & 0.282 & 1.144 & 1.335 \\
\hline $\mathrm{EC}$ & 0.054 & 0.949 & 1.141 & 0.160 & 0.977 & 1.137 & 0.150 & 1.041 & 1.274 \\
\hline $\mathrm{IMF}$ & -0.094 & 1.181 & 1.444 & 0.071 & 1.226 & 1.442 & -0.047 & 1.358 & 1.588 \\
\hline OECD & -0.001 & 0.948 & 1.182 & 0.068 & 0.941 & 1.155 & -0.048 & 1.161 & 1.431 \\
\hline Private & -0.148 & 0.969 & 1.277 & -0.048 & 0.989 & 1.274 & -0.092 & 1.098 & 1.391 \\
\hline Confindustria & -0.007 & 1.071 & 1.326 & -0.031 & 1.035 & 1.292 & -0.154 & 1.095 & 1.349 \\
\hline ENI & -0.208 & 0.945 & 1.282 & 0.036 & 1.016 & 1.311 & 0.039 & 1.117 & 1.435 \\
\hline Prometeia & -0.229 & 0.890 & 1.221 & -0.147 & 0.920 & 1.219 & -0.178 & 1.083 & 1.378 \\
\hline
\end{tabular}


Table 2. Analysis of the forecast accuracy of public and private agencies under different regimes of fiscal responsibility

\begin{tabular}{|c|c|c|c|c|c|c|c|c|c|}
\hline \multirow[t]{2}{*}{ Deficit current year } & \multicolumn{3}{|c|}{ Autumn forecasts (common 119 obs) } & \multicolumn{3}{|c|}{ Autumn forecasts (unbalanced 142 obs) } & \multicolumn{3}{|c|}{ Spring \& Autumn (unbalanced 259 obs) } \\
\hline & ME & MAE & RMSE & ME & MAE & RMSE & ME & MAE & RMSE \\
\hline Pool & -0.231 & 0.449 & 0.567 & -0.118 & 0.470 & 0.616 & -0.110 & 0.578 & 0.724 \\
\hline Low fiscal resp. & -0.307 & 0.442 & 0.522 & -0.109 & 0.558 & 0.703 & -0.225 & 0.663 & 0.797 \\
\hline Medium fiscal resp. & -0.177 & 0.454 & 0.596 & -0.123 & 0.415 & 0.554 & -0.035 & 0.522 & 0.672 \\
\hline Public & -0.169 & 0.431 & 0.541 & -0.054 & 0.439 & 0.581 & -0.039 & 0.528 & 0.658 \\
\hline Low fiscal resp. & -0.206 & 0.407 & 0.472 & -0.004 & 0.532 & 0.666 & -0.127 & 0.620 & 0.742 \\
\hline Medium fiscal resp. & -0.143 & 0.448 & 0.585 & -0.084 & 0.381 & 0.522 & 0.015 & 0.471 & 0.601 \\
\hline Private & -0.314 & 0.474 & 0.599 & -0.211 & 0.517 & 0.663 & -0.202 & 0.644 & 0.802 \\
\hline Low fiscal resp. & -0.443 & 0.489 & 0.583 & -0.256 & 0.595 & 0.751 & -0.344 & 0.716 & 0.860 \\
\hline Medium fiscal resp. & -0.223 & 0.463 & 0.611 & -0.182 & 0.465 & 0.599 & -0.104 & 0.593 & 0.759 \\
\hline
\end{tabular}

\begin{tabular}{|c|c|c|c|c|c|c|c|c|c|}
\hline \multirow[t]{2}{*}{ Deficit 1 year ahead } & \multicolumn{3}{|c|}{ Autumn forecasts (common 119 obs) } & \multicolumn{3}{|c|}{ Autumn forecasts (unbalanced 142 obs) } & \multicolumn{3}{|c|}{ Spring \& Autumn (unbalanced 259 obs) } \\
\hline & ME & MAE & RMSE & $\mathrm{ME}$ & MAE & RMSE & $\mathrm{ME}$ & MAE & RMSE \\
\hline Pool & -0.049 & 1.016 & 1.281 & 0.067 & 1.038 & 1.274 & 0.008 & 1.145 & 1.409 \\
\hline Low fiscal resp. & -0.523 & 1.054 & 1.229 & -0.292 & 1.113 & 1.276 & -0.466 & 1.227 & 1.405 \\
\hline Medium fiscal resp. & 0.282 & 0.989 & 1.316 & 0.293 & 0.990 & 1.272 & 0.290 & 1.092 & 1.412 \\
\hline Public & 0.025 & 1.051 & 1.284 & 0.145 & 1.072 & 1.274 & 0.056 & 1.181 & 1.423 \\
\hline Low fiscal resp. & -0.467 & 1.064 & 1.240 & -0.216 & 1.124 & 1.285 & -0.363 & 1.226 & 1.421 \\
\hline Medium fiscal resp. & 0.369 & 1.042 & 1.313 & 0.368 & 1.039 & 1.267 & 0.314 & 1.153 & 1.423 \\
\hline Private & -0.148 & 0.969 & 1.277 & -0.048 & 0.989 & 1.274 & -0.092 & 1.098 & 1.391 \\
\hline Low fiscal resp. & -0.597 & 1.040 & 1.215 & -0.398 & 1.098 & 1.265 & -0.591 & 1.228 & 1.386 \\
\hline Medium fiscal resp. & 0.166 & 0.918 & 1.318 & 0.182 & 0.917 & 1.280 & 0.256 & 1.008 & 1.396 \\
\hline
\end{tabular}


Table 3. Results of the Diebold-Mariano test based on the RMSE for individual forecasters versus the OECD

\begin{tabular}{|c|c|c|c|c|c|c|c|c|c|}
\hline \multirow[t]{2}{*}{ Deficit current year } & \multicolumn{3}{|c|}{ All } & \multicolumn{3}{|c|}{ Low fiscal responsibility } & \multicolumn{3}{|c|}{ Medium fiscal responsibility } \\
\hline & Obs & DM test & p-value & Obs & DM test & p-value & Obs & DM test & p-value \\
\hline MEF & 21 & 2.468 & 0.014 & 8 & 1.145 & 0.252 & 13 & 4.080 & 0.000 \\
\hline $\mathrm{EC}$ & 42 & 2.019 & 0.044 & 16 & 1.357 & 0.175 & 26 & 1.190 & 0.234 \\
\hline $\mathrm{IMF}$ & 42 & 0.771 & 0.440 & 16 & 2.630 & 0.009 & 26 & -0.771 & 0.441 \\
\hline Confindustria & 31 & 1.645 & 0.100 & 14 & 2.105 & 0.035 & 17 & 0.498 & 0.618 \\
\hline ENI & 41 & 2.885 & 0.004 & 16 & 1.970 & 0.049 & 25 & 2.106 & 0.035 \\
\hline Prometeia & 40 & 3.462 & 0.001 & 16 & 2.857 & 0.004 & 24 & 1.943 & 0.052 \\
\hline
\end{tabular}

\begin{tabular}{|c|c|c|c|c|c|c|c|c|c|}
\hline \multirow[t]{2}{*}{ Deficit 1 year ahead } & \multicolumn{3}{|c|}{ All } & \multicolumn{3}{|c|}{ Low fiscal responsibility } & \multicolumn{3}{|c|}{ Medium fiscal responsibility } \\
\hline & Obs & DM test & p-value & Obs & DM test & p-value & Obs & DM test & p-value \\
\hline $\mathrm{MEF}$ & 21 & 2.400 & 0.016 & 8 & 0.887 & 0.375 & 13 & 2.856 & 0.004 \\
\hline $\mathrm{EC}$ & 42 & -1.458 & 0.145 & 16 & -1.307 & 0.191 & 26 & -1.496 & 0.135 \\
\hline IMF & 42 & 1.951 & 0.051 & 16 & 1.532 & 0.126 & 26 & 1.352 & 0.177 \\
\hline Confindustria & 31 & -0.159 & 0.874 & 14 & -1.422 & 0.155 & 17 & 1.372 & 0.170 \\
\hline ENI & 41 & -0.039 & 0.969 & 16 & -0.442 & 0.658 & 25 & 0.393 & 0.694 \\
\hline Prometeia & 40 & -0.785 & 0.433 & 16 & -0.464 & 0.643 & 24 & -0.614 & 0.540 \\
\hline
\end{tabular}


Table 4. Analysis of the unbiasedness of the forecasts for the current year under different regimes of fiscal responsibility

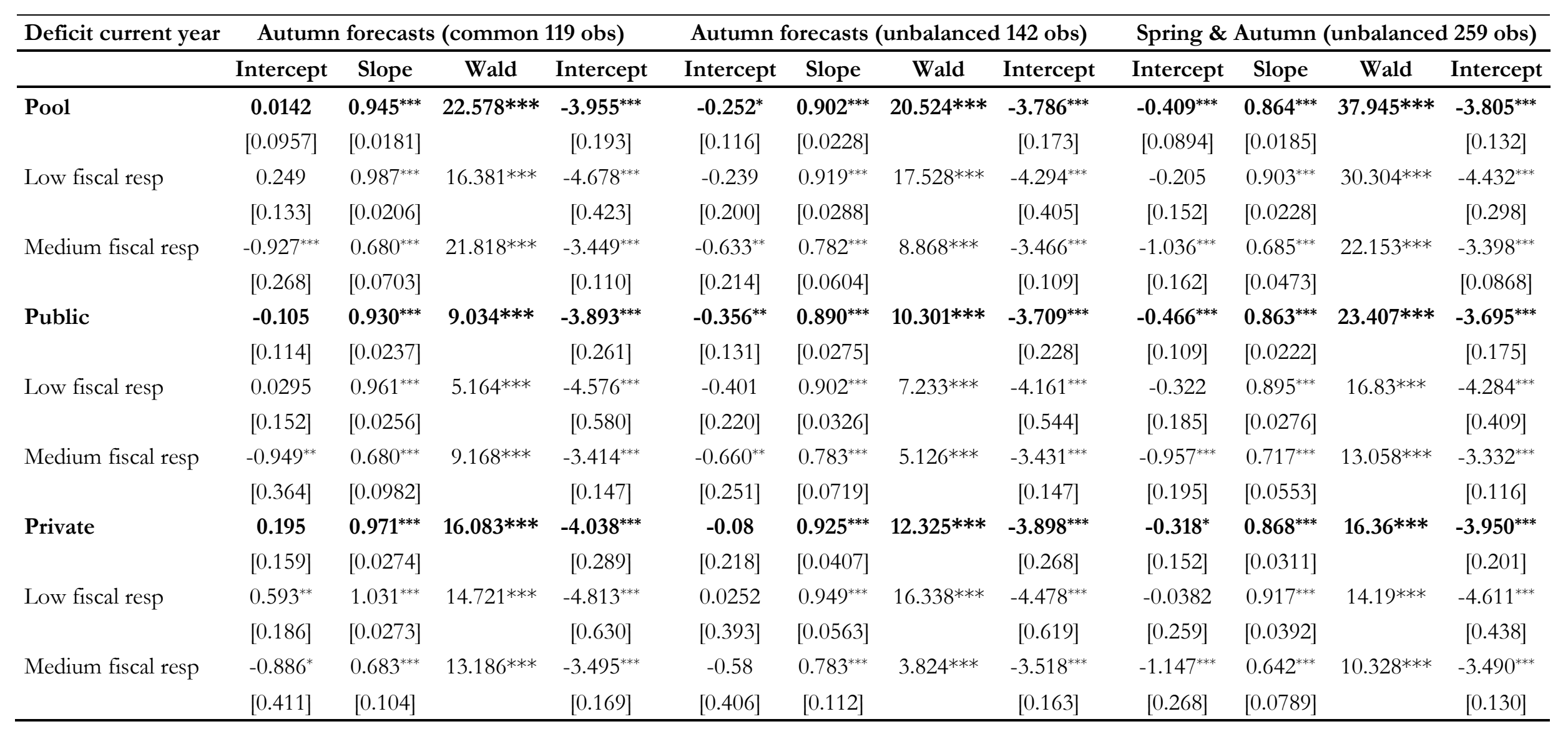


Table 5. Analysis of the unbiasedness of the forecasts for the year ahead under different regimes of fiscal responsibility

\begin{tabular}{|c|c|c|c|c|c|c|c|c|c|c|c|c|}
\hline \multirow[t]{2}{*}{ Deficit 1 year ahead } & \multicolumn{4}{|c|}{ Autumn forecasts (common 119 obs) } & \multicolumn{4}{|c|}{ Autumn forecasts (unbalanced 142 obs) } & \multicolumn{4}{|c|}{ Spring \& Autumn (unbalanced 259 obs) } \\
\hline & Intercept & Slope & Wald & Intercept & Intercept & Slope & Wald & Intercept & Intercept & Slope & Wald & Intercept \\
\hline \multirow[t]{2}{*}{ Pool } & $-1.130^{* * *}$ & $0.656^{* * *}$ & $32.454 * * *$ & $-3.427^{* * *}$ & $-1.365^{* * *}$ & $0.605^{* * *}$ & $50.777 * * *$ & $-3.290^{* * *}$ & $-1.511^{* * *}$ & $0.550^{* * *}$ & $98.135 * * *$ & $-3.378^{* * *}$ \\
\hline & [0.198] & {$[0.0441]$} & & {$[0.168]$} & {$[0.162]$} & {$[0.0392]$} & & {$[0.155]$} & {$[0.127]$} & {$[0.0321]$} & & {$[0.120]$} \\
\hline \multirow[t]{2}{*}{ Low fiscal resp } & -0.314 & $0.790^{* * *}$ & $19.878^{* * *}$ & $-3.984^{* * *}$ & $-0.712^{* *}$ & $0.724^{* * *}$ & $23.897 * * *$ & $-3.637^{* * *}$ & $-0.670^{* * *}$ & $0.702^{* * *}$ & $53.498 * * *$ & $-3.810^{* * *}$ \\
\hline & {$[0.282]$} & {$[0.0526]$} & & {$[0.370]$} & {$[0.243]$} & {$[0.0466]$} & & {$[0.356]$} & [0.183] & {$[0.0348]$} & & {$[0.265]$} \\
\hline \multirow[t]{2}{*}{ Medium fiscal resp } & $-3.234^{* * *}$ & 0.028 & $36.382^{* * *}$ & $-3.037^{* * *}$ & $-2.783^{* * *}$ & $0.189^{* *}$ & $69.485^{* * *}$ & $-3.070^{* * *}$ & $-3.041^{* * *}$ & $0.112^{*}$ & $158.955^{* * *}$ & $-3.097^{* * *}$ \\
\hline & {$[0.383]$} & {$[0.116]$} & & {$[0.0998]$} & {$[0.241]$} & {$[0.0705]$} & & {$[0.110]$} & {$[0.171]$} & {$[0.0529]$} & & [0.0918] \\
\hline \multirow[t]{2}{*}{ Public } & $-1.196^{* * *}$ & $0.651^{* * *}$ & $18.462 * * *$ & $-3.352^{* * *}$ & $-1.436^{* * *}$ & $0.597^{* * *}$ & $32.003 * * *$ & $-3.205^{* * *}$ & $-1.596^{* * *}$ & $0.532^{* * *}$ & $58.003 * * *$ & $-3.294^{* * *}$ \\
\hline & {$[0.254]$} & {$[0.0579]$} & & {$[0.226]$} & {$[0.201]$} & {$[0.0508]$} & & [0.203] & {$[0.163]$} & {$[0.0440]$} & & {$[0.160]$} \\
\hline \multirow[t]{2}{*}{ Low fiscal resp } & -0.414 & $0.776^{* * *}$ & $10.536 * * *$ & $-3.928^{* * *}$ & $-0.808^{* *}$ & $0.711^{* * *}$ & $13.393^{* * *}$ & $-3.544^{* * *}$ & $-0.797^{* * *}$ & $0.686^{* * *}$ & $24.725^{* * *}$ & $-3.692^{* * *}$ \\
\hline & {$[0.367]$} & {$[0.0689]$} & & {$[0.501]$} & [0.305] & {$[0.0605]$} & & {$[0.474]$} & {$[0.236]$} & {$[0.0483]$} & & {$[0.361]$} \\
\hline \multirow[t]{2}{*}{ Medium fiscal resp } & $-3.129^{* * *}$ & 0.0644 & $27.187^{* * *} *$ & $-2.950^{* * *}$ & $-2.695^{* * *}$ & $0.223^{* *}$ & $55.71 * * *$ & $-2.996^{* * *}$ & $-2.926^{* * *}$ & $0.144^{*}$ & $121.371 * * *$ & $-3.050^{* * *}$ \\
\hline & {$[0.435]$} & [0.128] & & {$[0.131]$} & {$[0.267]$} & {$[0.0750]$} & & {$[0.147]$} & {$[0.190]$} & {$[0.0587]$} & & {$[0.129]$} \\
\hline \multirow[t]{2}{*}{ Private } & $-1.027^{* *}$ & $0.667^{* * *}$ & $13.727 * * *$ & $-3.526^{* * *}$ & $-1.243^{* * *}$ & $0.622^{* * *}$ & $18.639 * * *$ & $-3.413^{* * *}$ & $-1.386^{* * *}$ & $0.576^{* * *}$ & $41.624 * * *$ & $-3.488^{* * *}$ \\
\hline & {$[0.324]$} & {$[0.0698]$} & & {$[0.253]$} & {$[0.277]$} & {$[0.0633]$} & & {$[0.240]$} & [0.205] & {$[0.0473]$} & & {$[0.181]$} \\
\hline \multirow[t]{2}{*}{ Low fiscal resp } & -0.168 & $0.811^{* * *}$ & $8.581 * * *$ & $-4.058^{* * *}$ & -0.563 & $0.745^{* * *}$ & $9.852^{* * *}$ & $-3.767^{* * *}$ & -0.495 & $0.725^{* * *}$ & $30.885^{* * *}$ & $-3.954^{* * *}$ \\
\hline & {$[0.460]$} & {$[0.0861]$} & & {$[0.562]$} & {$[0.417]$} & {$[0.0778]$} & & {$[0.550]$} & [0.293] & {$[0.0520]$} & & {$[0.394]$} \\
\hline \multirow[t]{2}{*}{ Medium fiscal resp } & $-3.378^{* * *}$ & -0.0189 & $11.611 * * *$ & $-3.153^{* * *}$ & $-2.939^{* * *}$ & 0.133 & $18.512^{* * *}$ & $-3.181^{* * *}$ & $-3.271^{* * *}$ & 0.0468 & $43.828^{* * *}$ & $-3.163^{* * *}$ \\
\hline & {$[0.706]$} & {$[0.214]$} & & {$[0.153]$} & {$[0.488]$} & {$[0.145]$} & & {$[0.166]$} & {$[0.350]$} & {$[0.107]$} & & {$[0.127]$} \\
\hline
\end{tabular}


Table 6. Analysis of the determinants of forecasts errors for the current year

\begin{tabular}{|c|c|c|c|c|c|c|c|c|c|}
\hline \multirow[t]{2}{*}{ Current year } & \multicolumn{3}{|c|}{ Autumn forecasts (common) } & \multicolumn{3}{|c|}{ Autumn forecasts (unbalance) } & \multicolumn{3}{|c|}{ Spring \& Autumn (unbalanced) } \\
\hline & All & Public & Private & All & Public & Private & All & Public & Private \\
\hline \multirow[t]{2}{*}{ GDP forecasts errors } & $0.612^{* * *}$ & $0.774^{* * *}$ & 0.190 & $0.224^{*}$ & $0.0485^{* *}$ & 0.0864 & $0.394^{* * *}$ & $0.300^{* * *}$ & $0.480^{* * *}$ \\
\hline & {$[0.134]$} & {$[0.216]$} & {$[0.215]$} & [0.0929] & {$[0.0161]$} & [0.193] & {$[0.0600]$} & {$[0.0428]$} & {$[0.0924]$} \\
\hline \multirow[t]{2}{*}{ Output gap (lagged) } & $-0.214^{* *}$ & $-0.312^{* * *}$ & -0.0333 & -0.0254 & -0.0259 & 0.0311 & -0.0488 & -0.000718 & $-0.108^{*}$ \\
\hline & {$[0.0655]$} & {$[0.0685]$} & {$[0.0866]$} & {$[0.0357]$} & {$[0.0526]$} & {$[0.0691]$} & {$[0.0371]$} & {$[0.0376]$} & {$[0.0480]$} \\
\hline \multirow[t]{2}{*}{ Debt (lagged) } & $-0.0782^{* * *}$ & $-0.101^{* * *}$ & -0.0323 & $-0.0379^{* *}$ & $-0.0531^{* *}$ & -0.0209 & $-0.0445^{* * *}$ & $-0.0312^{*}$ & $-0.0633^{* * *}$ \\
\hline & {$[0.0203]$} & {$[0.0283]$} & {$[0.0280]$} & [0.0132] & {$[0.0190]$} & {$[0.0190]$} & {$[0.0106]$} & [0.0139] & [0.0135] \\
\hline \multirow[t]{2}{*}{ Fiscal responsibility } & $-0.442^{* * *}$ & $-0.491^{* * *}$ & $-0.339^{*}$ & $-0.320^{* *}$ & $-0.488^{* * *}$ & $-0.198^{*}$ & $-0.162^{*}$ & -0.154 & -0.192 \\
\hline & {$[0.0806]$} & [0.134] & [0.168] & [0.103] & {$[0.142]$} & [0.0881] & [0.0819] & {$[0.140]$} & {$[0.126]$} \\
\hline \multirow[t]{2}{*}{ Good times } & $-0.533^{* * *}$ & $-0.459^{* * *}$ & $-0.640^{* * *}$ & $-0.475^{\text {*** }}$ & $-0.614^{* * *}$ & $-0.528^{* * *}$ & $-0.459^{* * *}$ & $-0.403^{* *}$ & $-0.565^{* *}$ \\
\hline & {$[0.0755]$} & {$[0.120]$} & {$[0.174]$} & [0.0866] & {$[0.112]$} & [0.142] & {$[0.0900]$} & [0.126] & {$[0.180]$} \\
\hline \multirow[t]{2}{*}{ Elections year } & $-0.494^{* * *}$ & $-0.622^{* * *}$ & -0.271 & 0.0607 & -0.100 & 0.238 & 0.00886 & -0.0244 & 0.0245 \\
\hline & {$[0.131]$} & {$[0.133]$} & {$[0.280]$} & {$[0.125]$} & {$[0.0812]$} & {$[0.331]$} & {$[0.0511]$} & {$[0.0614]$} & {$[0.0724]$} \\
\hline \multirow[t]{2}{*}{ Margin of majority } & -0.601 & -2.093 & 1.536 & $-3.023^{* *}$ & $-3.439^{* * *}$ & -2.332 & $-3.162^{* * *}$ & $-2.939^{* * *}$ & $-3.459^{*}$ \\
\hline & [1.316] & [2.344] & [1.052] & [1.024] & [0.958] & [2.253] & [0.697] & {$[0.540]$} & [1.557] \\
\hline Observations & 105 & 60 & 45 & 128 & 76 & 52 & 234 & 133 & 101 \\
\hline
\end{tabular}


Table 7. Analysis of the determinants of forecasts errors for the year ahead

\begin{tabular}{|c|c|c|c|c|c|c|c|c|c|}
\hline \multirow[t]{2}{*}{1 year ahead } & \multicolumn{3}{|c|}{ Autumn forecasts (common) } & \multicolumn{3}{|c|}{ Autumn forecasts (unbalance) } & \multicolumn{3}{|c|}{ Spring \& Autumn (unbalanced) } \\
\hline & All & Public & Private & All & Public & Private & All & Public & Private \\
\hline \multirow{2}{*}{ GDP forecasts errors } & $0.650^{* * *}$ & $0.651^{* * *}$ & $0.635^{* * *}$ & $0.653^{* * *}$ & $0.648^{* * *}$ & $0.644^{* * *}$ & $0.627^{* * *}$ & $0.652^{* * *}$ & $0.594^{* * *}$ \\
\hline & {$[0.0524]$} & {$[0.0965]$} & {$[0.0670]$} & {$[0.0512]$} & {$[0.0930]$} & {$[0.0630]$} & {$[0.0386]$} & {$[0.0567]$} & {$[0.0500]$} \\
\hline \multirow{2}{*}{ Output gap } & -0.171 & -0.192 & -0.137 & -0.0806 & -0.0447 & -0.130 & $-0.208^{* *}$ & -0.124 & $-0.324^{*}$ \\
\hline & {$[0.0898]$} & {$[0.138]$} & {$[0.143]$} & {$[0.0853]$} & [0.112] & {$[0.146]$} & {$[0.0769]$} & {$[0.0762]$} & {$[0.151]$} \\
\hline \multirow[t]{2}{*}{ Debt } & $-0.0886^{* *}$ & $-0.102^{*}$ & $-0.0711^{*}$ & $-0.0622^{* *}$ & -0.0590 & -0.0647 & $-0.0967^{* * *}$ & $-0.0772^{* *}$ & $-0.123^{* *}$ \\
\hline & {$[0.0271]$} & {$[0.0448]$} & {$[0.0349]$} & {$[0.0227]$} & {$[0.0304]$} & {$[0.0393]$} & {$[0.0210]$} & {$[0.0242]$} & {$[0.0388]$} \\
\hline \multirow[t]{2}{*}{ Fiscal responsibility } & -0.142 & -0.119 & -0.165 & 0.0221 & 0.0587 & 0.0122 & 0.122 & 0.0290 & 0.243 \\
\hline & {$[0.0810]$} & {$[0.135]$} & {$[0.122]$} & {$[0.112]$} & {$[0.172]$} & {$[0.216]$} & {$[0.152]$} & {$[0.266]$} & {$[0.178]$} \\
\hline \multirow[t]{2}{*}{ Good times } & $-0.563^{* * *}$ & $-0.426^{*}$ & $-0.765^{* * *}$ & $-0.629^{* * *}$ & $-0.565^{* * *}$ & $-0.740^{* * *}$ & $-0.656^{* * *}$ & $-0.680^{* * *}$ & $-0.630^{*}$ \\
\hline & {$[0.147]$} & {$[0.207]$} & {$[0.180]$} & {$[0.100]$} & {$[0.120]$} & {$[0.187]$} & {$[0.150]$} & {$[0.189]$} & {$[0.313]$} \\
\hline \multirow[t]{2}{*}{ Elections year } & $-0.500^{* * *}$ & -0.394 & $-0.641^{* * *}$ & $-0.295^{*}$ & -0.305 & -0.287 & $-0.255^{*}$ & $-0.392^{* *}$ & -0.0634 \\
\hline & {$[0.145]$} & {$[0.254]$} & {$[0.0478]$} & [0.115] & [0.183] & [0.147] & [0.119] & {$[0.120]$} & [0.188] \\
\hline \multirow{2}{*}{ Margin of majority } & $-4.761^{* * *}$ & $-5.054^{*}$ & $-4.422^{*}$ & $-7.285^{* * *}$ & $-6.962^{* * *}$ & $-7.876^{* *}$ & $-8.632^{* * *}$ & $-7.744^{* * *}$ & $-9.842^{* * *}$ \\
\hline & [1.225] & [1.986] & [1.909] & {$[1.257]$} & {$[1.567]$} & {$[2.810]$} & {$[1.050]$} & [1.258] & [1.968] \\
\hline Observations & 105 & 60 & 45 & 128 & 76 & 52 & 234 & 133 & 101 \\
\hline
\end{tabular}


Hence, in Italy, during the period considered, the SGP rules did not contribute to reduce the presence of an optimistic bias in deficit projections of both public and private forecasters. This is consistent with Frankel and Schreger (2013) results of a relationship between the SGP rules and over-optimistic forecasts. European controls could be behind optimistic forecasts in Italy as the government could use them to avoid or postpone reprimands. On the contrary, they found that the bias was reduced by stronger national rules. Some of these national rules were missing in Italy during our period of analysis, in particular the existence of an independent fiscal authority. The fact that the independent fiscal authority (the parliamentary budget office) became operational only in 2014 might explain this result. Frankel and Schreger (2013) estimated that forecasting bias is reduced by over $2 \%$ of GDP in euro members when independent fiscal institutions provide independent budget balance forecasts.

\section{Conclusions}

In this paper, we focused on an analysis of forecast deficits, expressed as a ratio relative to GDP, made by public and private agencies from the years 1994 to 2014 for the Italian budget deficit. We compared the current year forecast and the year ahead forecast and their relative forecast errors for public and private agencies under different levels of fiscal responsibility.

As many authors (Batchelor 2001, Abreu 2011, Frankel, 2011 and Frankel and Schreger 2013, 2016, Merola and Pérez, 2013) argue, the results in our paper also confirm that the budget-making process could possibly be improved by using a pool of forecasters including both public and private. However, our results indicate that the increase in fiscal responsibility did not contribute to reduce the optimistic bias in fiscal forecasts. Fiscal forecasters did not seem to learn from fiscal rules. The fact that national fiscal rules were adopted relatively late in Italy could explain partly this result, since as Frankel and Schreger (2013) showed, European controls tend to increase the optimistic bias of public forecasts while national rules reduce it. Similarly, the margin of majority, which has been promoted in Italy (and other European countries) by political reforms, has not contributed to a reduction of the optimistic bias of fiscal forecasts, as when political fragmentation is reduced, the optimistic bias increases.

Last, it is worth mentioning that our results could change in the future as the level of fiscal responsibility has only significantly increased at the end of our sample. If it takes time to forecasters to learn from the adoption and implementation of fiscal rules, fiscal forecast accuracy could improve in the future. This is an issue that could be explored in future research. 


\section{References}

Abreu, L. (2011). International Organizations' vs. private analysts' forecasts: an evaluation, Banco de Portugal Working Paper No. 20.

Artis, M., \& Marcellino, M. (1998). Fiscal solvency and fiscal Forecasting in Europe, CEPR Discussion Paper No. 1836.

Artis, M., \& Marcellino, M. (2001). Fiscal forecasting: the track record of the IMF, OECD and EC. Econometrics Journal, 4, 20-36.

Barroso Vasconcelos de Deus, J. D. \& Ferreira de Mendonça, H. (2015). Empirical evidence on fiscal forecasting in Eurozone countries, Journal of Economic Studies, 42, $838-860$.

Batchelor, R., (2001). How useful are the forecasts of intergovernmental agencies? The IMF and OECD versus the consensus, Applied Economics, 33, 225 - 35.

Beck, T., Clarke, G., Groff, A., Keefer, P. \& Walsh, P. (2001). New tools in comparative political economy: the database of political institutions. The World Bank Economic Review, 15, 165-176.

Beetsma, R., Bluhm, B., Giuliodori, M. \& Wierts, P. (2013). From budgetary forecasts to ex-post fiscal data: exploring the evolution of fiscal forecast errors in the EU, Contemporary Economic Policy, 31, 795-813

Bruch, T. and Stephan, A. (2006). Do Euro zone countries Cheat with Their Budget Deficit Forecasts?. Ky/klos, 59, 3-15

Buettner, T., \& Kauder, B. (2015). Political biases despite external expert participation? An empirical analysis of tax revenue forecasts in Germany, Public Choice, 164, pp. 287-307.

Clements, M.P., \& Hendry, D.F. (1997). Intercept corrections and structural change. Journal of Applied Econometrics, 11, 475-494.

Debrun, X., Hauner, D. \& Kumar, M.S. (2009). Independent fiscal agencies. Journal of Economic Surveys 23, 44-81.

Diebold, F.X., \& Mariano, R.S. (1995). Comparing predictive accuracy. Journal of Business and Economic Statistics, 13 (3), 253-263.

Favero, C., \& Marcellino, M. (2005). Modelling and forecasting fiscal variables for the Euro Area. Oxford Bulletin of Economics and Statistics, 67, 755-783. 
Figari, F. \& Fiorio, C. V. (2015). Fiscal consolidation policies in the context of Italy's two recessions, Fiscal Studies, 36, 499-526.

Frankel, J. A. (2011). Over-optimism in forecasts by official budget agencies and its implications, Oxford Review of Economic Policy, 4, 536-562

Frankel, J. A., \& Schreger, J. (2013). Over-optimistic official forecasts and fiscal rules in the Eurozone, Review of World Economics, 149, 247-272.

Frankel, J. A., \& Schreger, J. (2016). Bias in official fiscal forecasts: can private forecasts help?, NBER Working Paper 22349, Cambridge, MA.

Giuliodori, M. \& Beetsma, R. (2008). On the relationship between fiscal plans in the European Union: an empirical analysis based on real-time data, Journal of Comparative Economics, 36 (2), 221-242.

Ghysels, E., \& Ozkan, N. (2015). Real-time forecasting of the US federal government budget: A simple mixed frequency data regression approach, International Journal of Forecasting, 31, 1009-1020.

Holden, K., \& Peel, D.A. (1990). On testing for unbiasedness and efficiency of forecasts. The Manchester School, 58 (2), 120 -127.

Jalles, J. T.,Karibzhanov, I. \& Loungani, P. (2015). Cross-country evidence on the quality of private sector fiscal forecasts, Journal of Macroeconomics, 45, 186-201.

Jonung, L. \& Larch, M. (2006). Fiscal policy in the EU: are official output forecasts biased? Economic Policy, 491-534.

Keereman, F. (1999). The track record of the Commission forecasts. EC, Directorate-General for Economic and Financial Affairs Economic Paper No. 137.

Merola, R., \& Pérez, J. J. (2013). Fiscal forecast errors: Governments versus independent agencies? European Journal of Political Economy, 32, 285-299.

Pedregal, D., \& Pérez, J. J. (2010). Should quarterly government finance statistics be used for fiscal surveillance in Europe?, International Journal of Forecasting, 26, 794-804.

Pérez, J. J. (2007). Leading indicators for euro area government deficits, International Journal of Forecasting, 23, 259-275.

Pina, A. M. \& Venes, N. M. (2011). The political economy of EDP fiscal forecasts: An empirical assessment, European Journal of Political Economy, 27, 534-546.

Timmermann, A. (2007). An evaluation of the World Economic Outlook forecasts. IMF Staff Papers, 54 (1), 1-33. 
von Hagen, J. (2010). Sticking to fiscal plans: the role of institutions, Public Choice, 144 (3), 487-503. 


\section{Appendix 1. Description of data sources}

\begin{tabular}{|l|l|}
\hline Deficit on GDP forecasts & Data sources \\
\hline Ministry of Economy and Finance of Italy & $\begin{array}{l}\text { Documento di Economia e Finanza - DEF (spring), Nota di Aggiornamento del } \\
\text { Documento di Economia e Finanza (autumn) from 2011 to 2015; } \\
\text { http://www.mef.gov.it/documenti-pubblicazioni/doc-finanza-pubblica/ }\end{array}$ \\
$\begin{array}{l}\text { Documento di Programmazione Economico - Finanziaria - DPEF from 1992-2010 } \\
\text { http://www.dt.tesoro.it/it/attivita istituzionali/analisi programmazione economico finan } \\
\text { ziaria/documenti programmatici/sezione1/dpef.html }\end{array}$ \\
\hline OECD & $\begin{array}{l}\text { OECD Economic Outlook } \\
\text { http://stats.oecd.org/index.aspx?DataSetCode=EO }\end{array}$ \\
\hline IMF & $\begin{array}{l}\text { World Economic Outlook Database } \\
\text { https://www.imf.org/external/pubs/ft/weo/2016/02/weodata/index.aspx }\end{array}$ \\
\hline EC & $\begin{array}{l}\text { Statistical Annex of European Economy } \\
\text { http://ec.europa.eu/economy finance/db indicators/statistical annex/index en.htm }\end{array}$ \\
\hline ENI & $\begin{array}{l}\text { Consensus Economics Forecasts } \\
\text { http://www.consensuseconomics.com/ }\end{array}$ \\
\hline Prometeia &
\end{tabular}




\begin{tabular}{|l|l|}
\hline Variable & Data sources \\
\hline Government deficit as a percentage of GDP & $\begin{array}{l}\text { OECD - OECD ilibrary } \\
\text { http://www.oecd-ilibrary.org/economics/economics-key-tables-from-oecd 2074384x }\end{array}$ \\
\hline Deficit on GDP and GDP growth - Vintage & $\begin{array}{l}\text { Economic Outlook Annual Projections for OECD Countries (different editions) } \\
\text { https://stats.oecd.org/Index.aspx?DataSetCode=EO49 VINTAGE }\end{array}$ \\
\hline $\begin{array}{l}\text { GDP growth, Output gap, } \\
\text { Public debt as a percentage of GDP }\end{array}$ & $\begin{array}{l}\text { OECD Economic Outlook } \\
\text { http://stats.oecd.org/index.aspx?DataSetCode=EO }\end{array}$ \\
\hline Fiscal responsibility, Margin of Majority & $\begin{array}{l}\text { World Bank Database of Political Institution } \\
\text { http://econ.worldbank.org/WBSITE/EXTERNAL/EXTDEC/EXTRESEARCH/0, con } \\
\text { tentMDK:20649465 pagePK:64214825 piPK:64214943 theSitePK:469382,00.html }\end{array}$ \\
\hline
\end{tabular}

